University of Wollongong

Research Online

Faculty of Engineering and Information

Faculty of Engineering and Information

Sciences - Papers: Part A

Sciences

$1-1-2010$

\title{
Influence of hydrogen content on hot deformation behavior and microstructural evolution of Ti600 alloy
}

J W. Zhao

Northeastern University, jzhao@uow.edu.au

H Ding

Northeastern University

H L. Hou

Beijing Aeronautical Manufacturing Technology Research Institute

Z Q. Li

Beijing Aeronautical Manufacturing Technology Research Institute

Follow this and additional works at: https://ro.uow.edu.au/eispapers

Part of the Engineering Commons, and the Science and Technology Studies Commons

Research Online is the open access institutional repository for the University of Wollongong. For further information contact the UOW Library: research-pubs@uow.edu.au 


\title{
Influence of hydrogen content on hot deformation behavior and microstructural evolution of Ti600 alloy
}

\author{
Abstract \\ Isothermal hot compression tests of a Ti600 alloy after hydrogenation were carried out over the \\ temperature range of 760 to $880^{\circ} \mathrm{C}$ and strain rate range of 0.01 to $10 \mathrm{~s}-1$. The influence of hydrogen \\ content was studied on the flow stress and activation energy of deformation. The microstructural \\ changes were examined by transmission electron microscopy (TEM). The results show that the addition \\ of $0.3 \%$ hydrogen in Ti600 alloy can decrease the hot deformation temperature by $80 \circ \mathrm{C}$ and increase the \\ deformation strain rate by two orders of magnitude. Both the flow stress and activation energy of \\ deformation of Ti600 alloy decrease gradually with increasing hydrogen content in the hydrogen range of \\ 0 to $0.3 \%$. TEM observation suggests that dynamic recrystallization (DRX) is promoted after \\ hydrogenation. Hydrides $\delta$ (fcc structure) exist in the specimens with $0.3 \%$ and $0.5 \%$ hydrogen, and the \\ hydrides tend to be broken up and twisted with increasing hydrogen content after deformation. The \\ mechanism of hydrogen reduced flow stress of Ti600 alloy has been discussed in detail.
}

\section{Keywords}

ti600, evolution, microstructural, behavior, alloy, deformation, influence, hot, content, hydrogen

\author{
Disciplines \\ Engineering | Science and Technology Studies
}

\section{Publication Details}

Zhao, J. W., Ding, H., Hou, H. L. \& Li, Z. Q. (2010). Influence of hydrogen content on hot deformation behavior and microstructural evolution of Ti600 alloy. Journal of Alloys and Compounds, 491 673-678. 


\title{
Influence of hydrogen content on hot deformation behavior and microstructural evolution of Ti600 alloy
}

\author{
J.W. Zhao ${ }^{\mathrm{a}, *}$, H. Ding ${ }^{\text {a }}$, H.L. Hou ${ }^{\text {b }}$, Z.Q. Li ${ }^{\mathrm{b}}$ \\ a School of Materials and Metallurgy, Northeastern University, Shenyang 110004, China \\ b Beijing Aeronautical Manufacturing Technology Research Institute, Beijing 100024, China
}

\section{A R T I C L E I N F O}

\section{Article history:}

Received 23 March 2009

Accepted 5 November 2009

Available online 11 November 2009

\section{Keywords:}

Titanium alloy

Hydrogen

Hot deformation

Flow stress

Microstructure

\begin{abstract}
A B S T R A C T
Isothermal hot compression tests of a Ti600 alloy after hydrogenation were carried out over the temperature range of 760 to $880^{\circ} \mathrm{C}$ and strain rate range of 0.01 to $10 \mathrm{~s}^{-1}$. The influence of hydrogen content was studied on the flow stress and activation energy of deformation. The microstructural changes were examined by transmission electron microscopy (TEM). The results show that the addition of $0.3 \%$ hydrogen in Ti600 alloy can decrease the hot deformation temperature by $80^{\circ} \mathrm{C}$ and increase the deformation strain rate by two orders of magnitude. Both the flow stress and activation energy of deformation of Ti600 alloy decrease gradually with increasing hydrogen content in the hydrogen range of 0 to $0.3 \%$. TEM observation suggests that dynamic recrystallization (DRX) is promoted after hydrogenation. Hydrides $\delta$ (fcc structure) exist in the specimens with $0.3 \%$ and $0.5 \%$ hydrogen, and the hydrides tend to be broken up and twisted with increasing hydrogen content after deformation. The mechanism of hydrogen reduced flow stress of Ti600 alloy has been discussed in detail.
\end{abstract}

(c) 2009 Elsevier B.V. All rights reserved.

\section{Introduction}

Hydrogen has always been regarded as an impurity element in titanium alloys, and even relatively low concentrations of hydrogen can lead to material failure if hydrogen is trapped around structural defects and local concentrations exceed a critical value [1-9]. However, positive influences of hydrogen on the production and processing of titanium alloys can also be utilized in some cases. Since Zwicker and Schleicher found that the addition of proper content of hydrogen could improve plasticity of titanium alloys, the influence of hydrogen on hot workability has been an important research topic all along [10-13]. Hydrogen has being considered as an especial element in titanium alloys, which can be easily added and removed without melting. After hydrogenation in titanium alloys, the phase transition $(\alpha+\beta) / \beta$ temperature is decreased, and ratio of $\beta$ increasing. Because $\beta$ phase, with bcc (body-centered cubic) structure, can be easily deformed at high temperature, the use of hydrogen as a temporary alloying element is always added into titanium alloys during hot deformation processing. In the 1970 s, scholars in former Soviet Union began to investigate the influence of hydrogen on thermo-plasticity of titanium alloys, and it had been found that the addition of hydrogen could reduce the flow stress and enhance the plasticity of $\alpha$, near- $\alpha$, $\alpha+\beta$ and intermetallic-base alloys [13-16]. The work of Kolachov

\footnotetext{
* Corresponding author. Tel.: +8624 83687746.

E-mail address: jwzhaocn@gmail.com (J.W. Zhao).
}

[17] showed that the flow stress after hydrogenation was only $1 / 3$ of that without hydrogen after $0.6 \%$ (mass fraction) hydrogen was added into the $\mathrm{Ti}_{3} \mathrm{Al}$ based CT5 alloy, moreover, there was no crack occurred even though $80 \%$ deformation was carried out at $900^{\circ} \mathrm{C}$. After $0.2 \%$ (mass fraction) hydrogen was charged in the Ti-14Al$19 \mathrm{Nb}-3 \mathrm{~V}-2 \mathrm{Mo}$ alloy, the deformation temperature was lowered by about $50^{\circ} \mathrm{C}$ and the strain rate was increased by one order of magnitude [18]. Tensile deformation tests were carried out by Zhang [19], the results of which revealed that the flow stress was decreased and the plasticity was improved when hydrogen content was less than $0.32 \%$ (mass fraction). Zong [20] suggested that the addition of $0.3 \%$ (mass fraction) hydrogen in Ti-6Al-4V alloy could decrease the flow stress by $11.2 \%$ and increase the plasticity by $20 \%$. Recently, an increased interesting on thermohydrogen treatment (THT), or the use of hydrogen as a temporary element for modifying microstructure and enhancing mechanical properties of titanium alloys, has been put great emphasize [21-24].

The materials used for aircraft engine are required to work stably in a long-term load with temperature range of 550 to $600^{\circ} \mathrm{C}$. At the present time, the typical titanium alloys meet such application are Ti-1100 alloy (U.S.) [25], IMI834 alloy (U.K.) [26] and BT36 alloy (Russia) [27], and these alloys have been used successfully on different aircraft engines. Ti600 alloy is a new type of near- $\alpha$ high-temperature titanium alloy which can work stably at $600^{\circ} \mathrm{C}$, and it has been regarded as one of the materials for aircraft engine serviced at the temperature $600^{\circ} \mathrm{C}$. However, because of the poor plasticity, Ti600 alloy as well as other high-temperature titanium alloys cannot be deformed by using conventional process- 

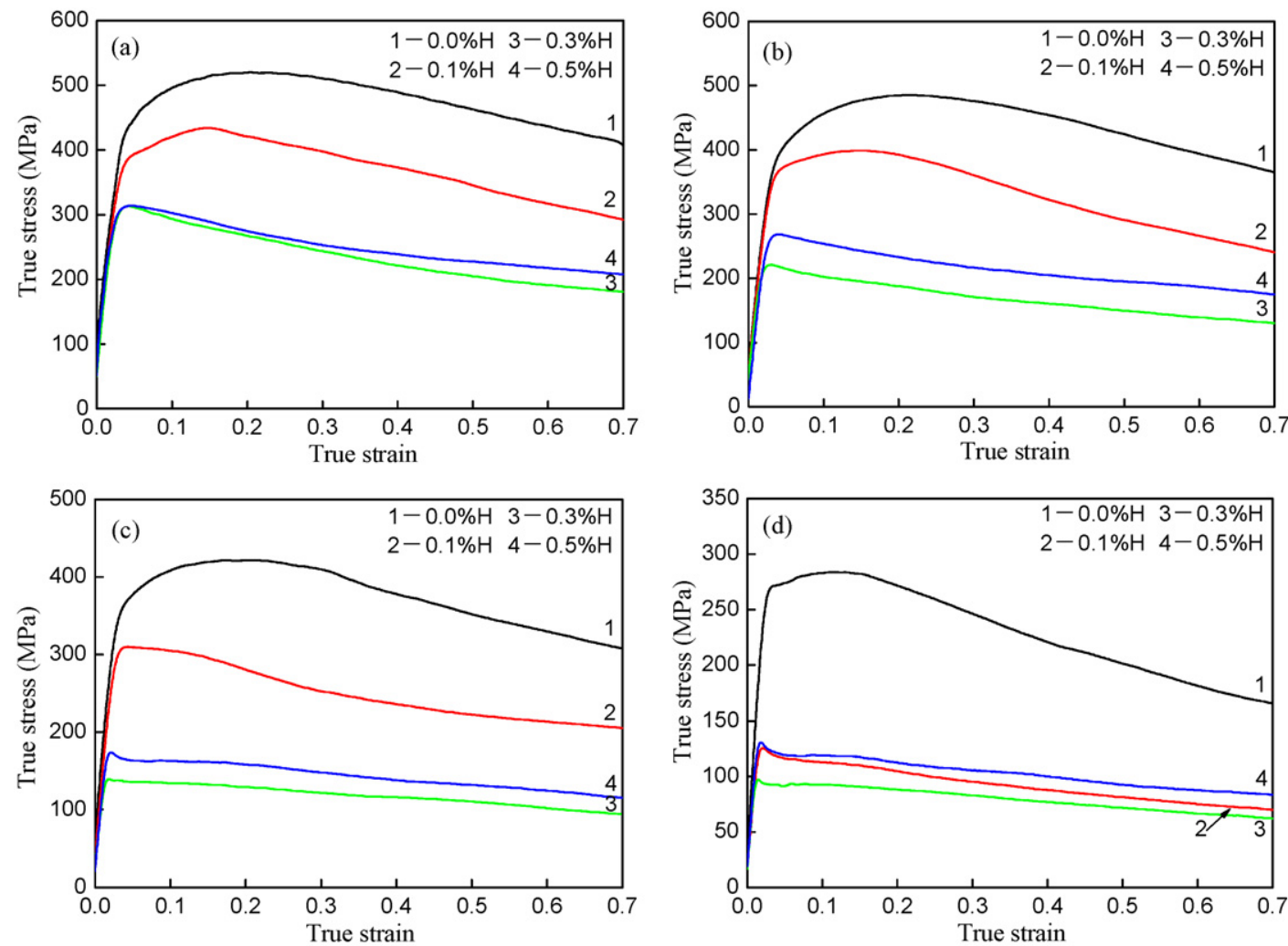

Fig. 1. Influence of hydrogen on flow stress (a) $T=760^{\circ} \mathrm{C}$; (b) $T=800^{\circ} \mathrm{C}$; (c) $T=840^{\circ} \mathrm{C}$; (d) $T=880^{\circ} \mathrm{C}$. $\dot{\varepsilon}=0.1 \mathrm{~s}^{-1}$.

ing method. Differently, by using THT technology, the addition of some hydrogen can remarkably decrease the flow stress of these alloys which make the deformation process possibility at relatively low temperature. The study on rolling process, thermal deformation behavior and creep theory of Ti600 alloy have currently received much attention [28-30]. However, the influence of hydrogenation on both hot deformation behavior and microstructural evolution of Ti600 alloy has not been investigated systematically. The objective of this work is to investigate the influence of hydrogen content on the hot deformation characteristics, including flow tress, microstructural evolution and activation energy of Ti600 alloy, with specific discussion on the mechanism of hydrogen reduced flow stress.

\section{Materials and experimenta}

The material used in this investigation was a Ti600 alloy, the chemical composition of which was as follows (in mass fraction, \%): $6 \mathrm{Al}, 2.8 \mathrm{Sn}, 4 \mathrm{Zr}, 0.5 \mathrm{Mo}$, $0.4 \mathrm{Si}, 0.1 \mathrm{Y}$ and the rest Ti. Cylindrical specimens $8 \mathrm{~mm}$ in diameter and $15 \mathrm{~mm}$ in height were prepared. The specimens were hydrogenated at $750^{\circ} \mathrm{C}$ by holding in a pure hydrogen environment for $2 \mathrm{~h}$ followed by air-cooling to room temperature. Specimens with various contents of hydrogen in the range of 0 to $0.5 \%$ (mass fraction) were obtained by controlling the hydrogen pressure, and the actual hydrogen content in specimen was determined by weighing the specimen before and after hydrogenation.

The hot deformation tests were performed on a Hot-simulator over the range of deformation temperature from 760 to $880^{\circ} \mathrm{C}$, strain rate from 0.01 to $10 \mathrm{~s}^{-1}$, and maximum true strain to 0.69 . The deformation process was controlled by computer, and all the tested data was collected automatically. In order to minimize friction and barrel development during deformation and to prevent bonding of the specimens to the anvils, graphitic lubricant was applied to the mating surfaces. Senkov and Jonas [31] found that when heated in air, hydrogen in titanium specimen could be retained at temperatures up to $980^{\circ} \mathrm{C}$ due to the formation of an oxidized film on the specimen surface, which prevented the escape of hydrogen from the specimen, also, no increases in the amounts of $\mathrm{O}$ and $\mathrm{N}$ were found in specimens after testing at $1000^{\circ} \mathrm{C}$ in air. All the tests therefore were performed in air in the present work. The transmission electron microscopy (TEM) specimens were prepared by electropolishing in an electrolyte of 6 vol.\% $\mathrm{HCLO}_{4}+34$ vol. $\% \mathrm{C}_{4} \mathrm{H}_{9} \mathrm{OH}+60 \mathrm{vol} . \%$ $\mathrm{CH}_{3} \mathrm{OH}$, and the operating conditions were -35 to $-40^{\circ} \mathrm{C}, 50$ to $55 \mathrm{~V}$ and 30 to
$35 \mathrm{~mA}$. TEM observations were carried out under a TECNAL G 20 microscope operated at $200 \mathrm{kV}$.

\section{Results and discussion}

\subsection{Influence of hydrogen on flow stress}

Fig. 1 shows the influence of hydrogen on the flow stress deformed from 760 to $880^{\circ} \mathrm{C}$. The flow behavior exhibits an initial increase in the flow stress with increasing strain until a peak stress value beyond which there is a decrease in flow stress with increasing strain. In the temperature range of 760 to $840{ }^{\circ} \mathrm{C}$ (Fig. 1a-c), a steady region is achieved in which the flow stress is observed to remain nearly constant with increasing strain when the hydrogen content is more than $0.3 \%$. When deformed at $880^{\circ} \mathrm{C}$ (Fig. 1d), the addition of hydrogen in Ti600 alloy shows slight change in the flow stress with increasing strain. At a fixed temperature, the flow tress decreases gradually with increasing hydrogen content in the hydrogen range of 0 to $0.3 \%$. However, when the hydrogen content is more than $0.3 \%$, the flow stress increases with increasing hydrogen. Therefore, when the hydrogen content is within no other than a certain proper range can decrease the flow stress of Ti600 alloy, remarkably.

Fig. 2 indicates the dependence of peak stress on deformation temperature for the specimens with $0.3 \%$ and without hydrogen at various strain rates. It can be seen that the peak stresses of the specimens with and without hydrogen decrease with increasing temperature or decreasing strain rate. At the strain rates of 0.01 , 0.1 and $1 \mathrm{~s}^{-1}$, the peak stresses of specimens with $0.3 \% \mathrm{H}$ deformed at 760 and $800^{\circ} \mathrm{C}$ are less than those of specimens without hydrogen deformed at 840 and $880^{\circ} \mathrm{C}$, respectively. Moreover, at a fixed temperature, the peak stresses of specimens with $0.3 \% \mathrm{H}$ at $1 \mathrm{~s}^{-1}$ are less than those of specimens without hydrogen deformed at strain rates of both 0.01 and $0.1 \mathrm{~s}^{-1}$. Consequently, the addition of 


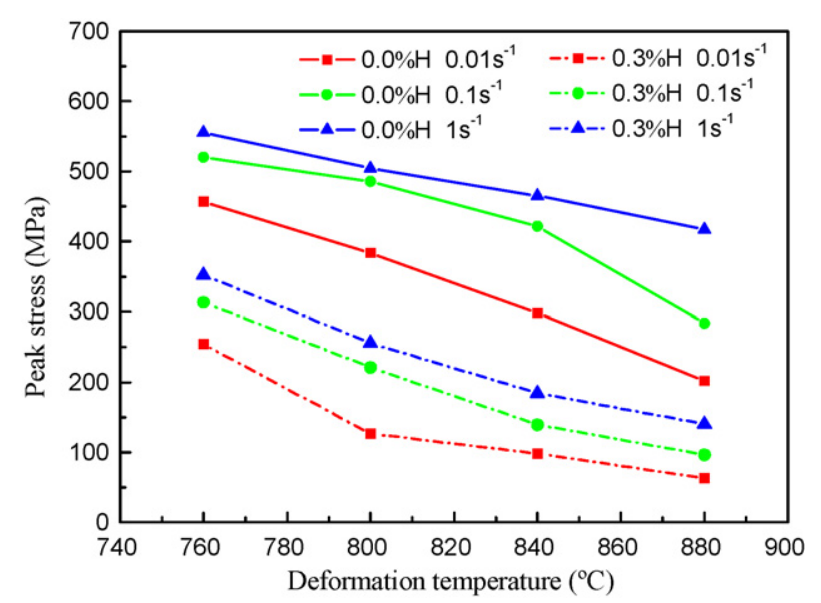

Fig. 2. Plots of peak stress vs. deformation temperature of Ti600 alloy at various strain rates.

\section{Table 1}

Rates of descent of peak stress at various deformed temperatures and strain rates after $0.3 \% \mathrm{H}$ is charged.

\begin{tabular}{lllll}
\hline \multicolumn{5}{c}{ Temperature $\left({ }^{\circ} \mathrm{C}\right)$} \\
\cline { 2 - 5 } & $760{ }^{\circ} \mathrm{C}$ & $800{ }^{\circ} \mathrm{C}$ & $840{ }^{\circ} \mathrm{C}$ & $880{ }^{\circ} \mathrm{C}$ \\
\hline $1 \mathrm{~s}^{-1}$ & $37 \%$ & $49 \%$ & $60 \%$ & $66 \%$ \\
$0.1 \mathrm{~s}^{-1}$ & $40 \%$ & $54 \%$ & $67 \%$ & $66 \%$ \\
$0.01 \mathrm{~s}^{-1}$ & $44 \%$ & $67 \%$ & $67 \%$ & $69 \%$ \\
\hline
\end{tabular}

$0.3 \%$ hydrogen in Ti600 alloy can decrease the hot deformation temperature by $80^{\circ} \mathrm{C}$ and increase the deformation strain rate by two orders of magnitude, in the temperature range of 760 to $880^{\circ} \mathrm{C}$ and at strain rates of $0.01,0.1$ and $1 \mathrm{~s}^{-1}$.

In comparison with the specimens without hydrogen, the rates of descent of peak stress of specimens with $0.3 \% \mathrm{H}$ deformed within the temperature range of 760 to $880^{\circ} \mathrm{C}$ and at the strain rates of 1 , 0.1 and $0.01 \mathrm{~s}^{-1}$ are tabulated in Table 1 . It can be seen that the rates of descent increase with increasing temperature or decreasing strain rate. And, the specimen deformed at $880^{\circ} \mathrm{C}$ and $0.01 \mathrm{~s}^{-1}$ shows a maximum drop in peak stress by $69 \%$ after $0.3 \% \mathrm{H}$ is charged.

\subsection{Influence of hydrogen on microstructural evolution}

The microstructures of specimens without and with hydrogen deformed at $800^{\circ} \mathrm{C}$ and $0.1 \mathrm{~s}^{-1}$ are illustrated in Figs. 3-5, respectively. The microstructures show a few of dislocations and $\alpha_{2}$ laths distribute in the specimen without hydrogen (Fig. 3a and b). Fig. 4a and b show dynamic recrystallization(DRX) grains in the specimens with $0.3 \% \mathrm{H}$ and $0.5 \% \mathrm{H}$, respectively. In the $0.3 \% \mathrm{H}$ specimen, the mean size of DRX grains is around $1 \mu \mathrm{m}$, with increasing hydrogen content from $0.3 \%$ to $0.5 \%$, the mean size decreases to about $0.3 \mu \mathrm{m}$, and the grain shape changes from equiaxed to banded one. Additionally, in the $0.3 \% \mathrm{H}$ specimen, $\alpha_{2}$ laths are gradually broken up into small $\alpha_{2}$ particles or short $\alpha_{2}$ laths (Fig. 4c). And, the $\alpha_{2}$ laths tend to be refined with increasing hydrogen content (Fig. 4d). After hydrogenated with $0.3 \% \mathrm{H}$ and $0.5 \% \mathrm{H}$, fcc (face-centered cubic, $a=0.444 \mathrm{~nm}$ ) hydrides $\delta$ appear (Fig. 5). In the specimen with $0.3 \% \mathrm{H}$, hydrides are all long lamellar and approximately parallel (Fig. 5a). When the hydrogen content increases up to $0.5 \%$, lamellar hydrides are broken up and twisted (Fig. 5c).

\subsection{Hydrogen-reduced flow stress mechanism}

At present, it has been generally suggested that the decrease of flow stress is related to the increase of $\beta$ phase. It is known that hydrogen alloying stabilizes the more ductile high temperature bcc $\beta$ phase in titanium, the $(\alpha+\beta) / \beta$ phase transition temperature is decreased, and the temperature interval of the two-phase $(\alpha+\beta)$ range is increased with addition of hydrogen. Because there are more slip systems in $\beta$ phase than those in $\alpha$ phase, a hydrogeninduced increase of $\beta$ phase will certainly lead to a decrease of flow stress, and also, an increase of the high-temperature plasticity. After hydrogenation, eutectoid reaction $\beta_{\mathrm{H}} \rightarrow \alpha+\delta$ happens, and then a new $\delta$ phase is formed. Because the specific volume of $\delta$ is different from that of $\beta$ matrix, stress fields are generated when $\delta$ precipitates from $\beta$ matrix, and then distortion of lattices are caused which leads to large numbers of dislocations exist around $\delta$. It has been observed $[32,33]$ that the hydrogen-induced softening of titanium is associated with the interaction of dislocations with hydrogen. When deformed at high temperature, hydrogen in solution in titanium lowers the strength of dislocation interactions with various obstacles, and dislocation mobility is enhanced, which leads to a decrease in flow stress. In addition, the hydrogen in solution, being highly mobile and occupying interstitial sites near dislocations, prevents other solutes from segregating to the mobile dislocations. Moreover, as the diffusion ability of alloying elements is increased, dynamic recovery and recrystallization are facilitated, lowering the flow stress in this way. Additionally, because the content of $\beta$ phase increases after hydrogenation, the concentration of the alloying element dissolved in $\beta$ phase is reduced, and the solution strength is weakened which may also cause the flow stress decrease to a certain extent.

Although the flow stress can be decreased effectively by an increase in the volume fraction of $\beta$ phase when the hydrogen content is within a certain range, the flow stress increases because of the coarsening of $\beta$ phase when the hydrogen content is high $(0.5 \%$
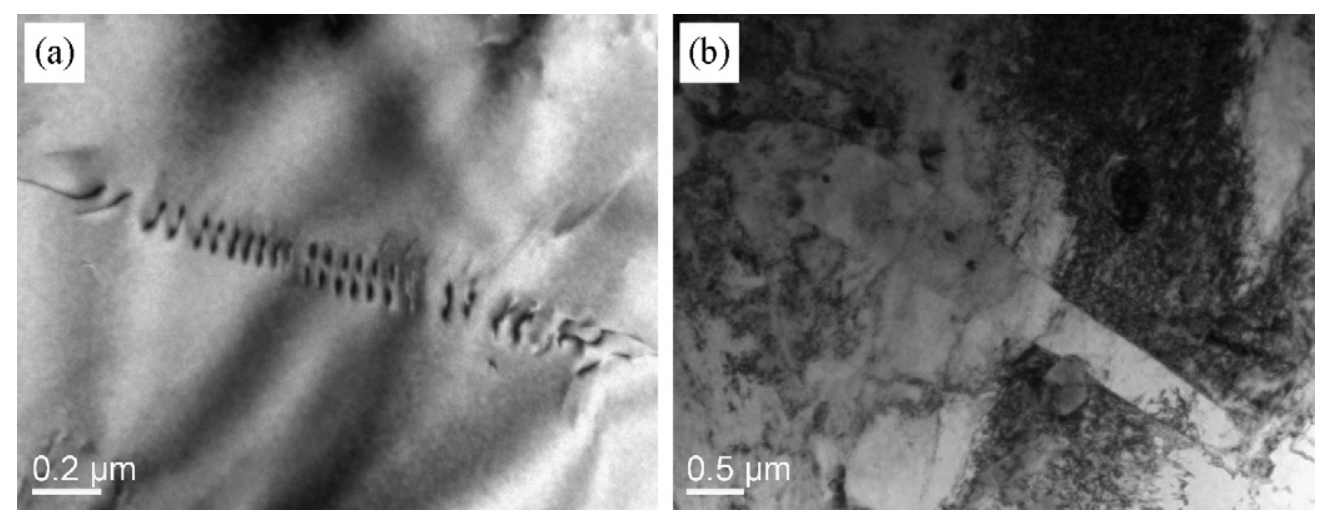

Fig. 3. TEM micrographs of Ti600 alloy without hydrogen deformed at $800^{\circ} \mathrm{C}$ and $0.1 \mathrm{~s}^{-1}$ (a) dislocations; (b) $\alpha_{2}$ lath. 

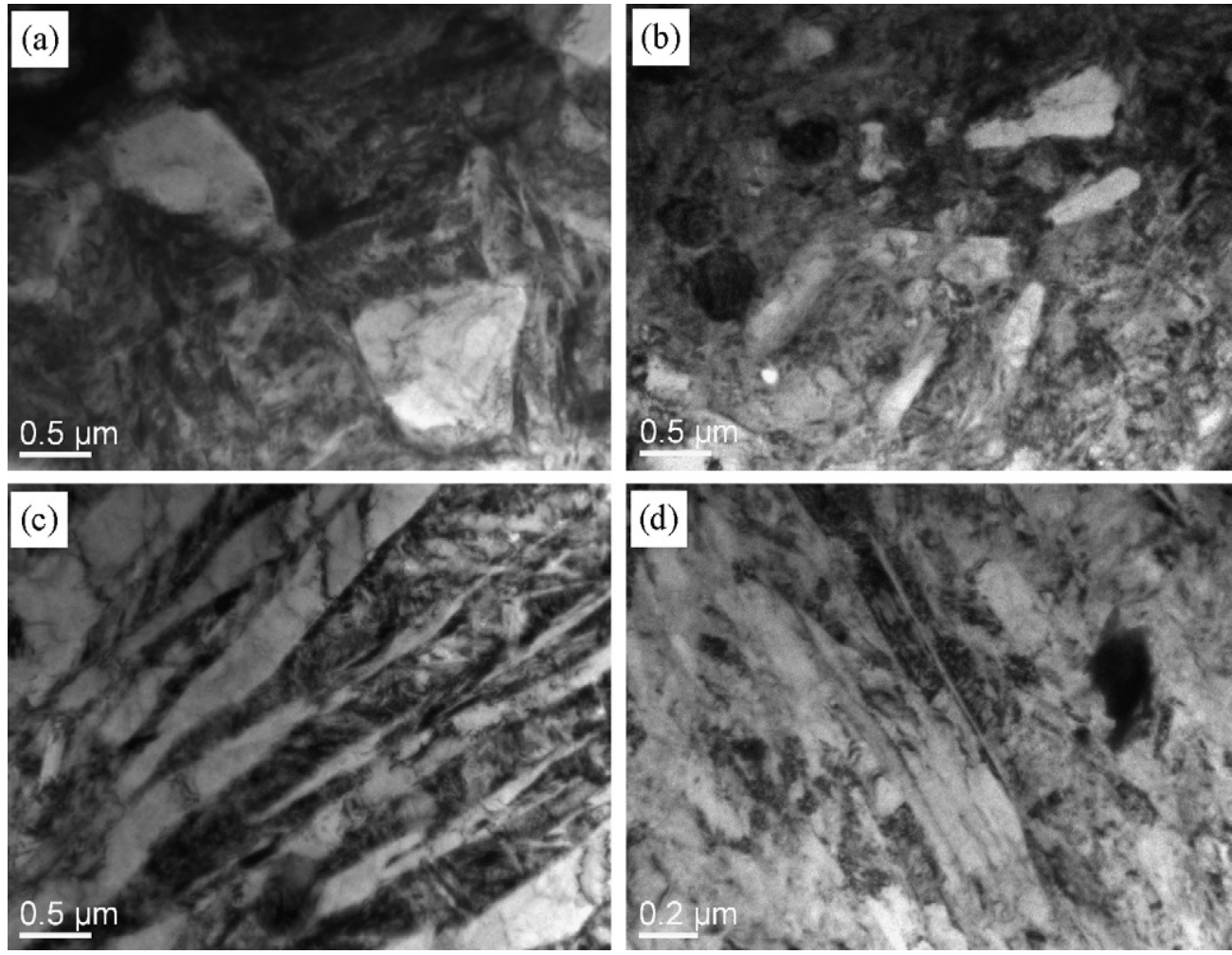

Fig. 4. TEM micrographs of $0.3 \% \mathrm{H}(\mathrm{a}, \mathrm{c})$ and $0.5 \% \mathrm{H}(\mathrm{b}, \mathrm{d})$ specimens deformed at $800^{\circ} \mathrm{C}$ and $0.1 \mathrm{~s}^{-1}$ (a, b) recrystallization grains; (c, d) lamellar structures.

$\mathrm{H}$ in the present work). In addition, the solubility of hydrogen in $\beta$ phase is far more than that in $\alpha$ phase, large numbers of hydrogen atoms enter the interstitial sites and function as solution strengthening at a higher hydrogen content. Meanwhile, the increase of flow stress is caused, at least partly, by an increase in the volume fraction of $\delta$ because of its function as a strengthening phase in Ti600 alloy. Moreover, when hydrogen content is relatively high, the broken and twisted hydrides appear in the specimen is another
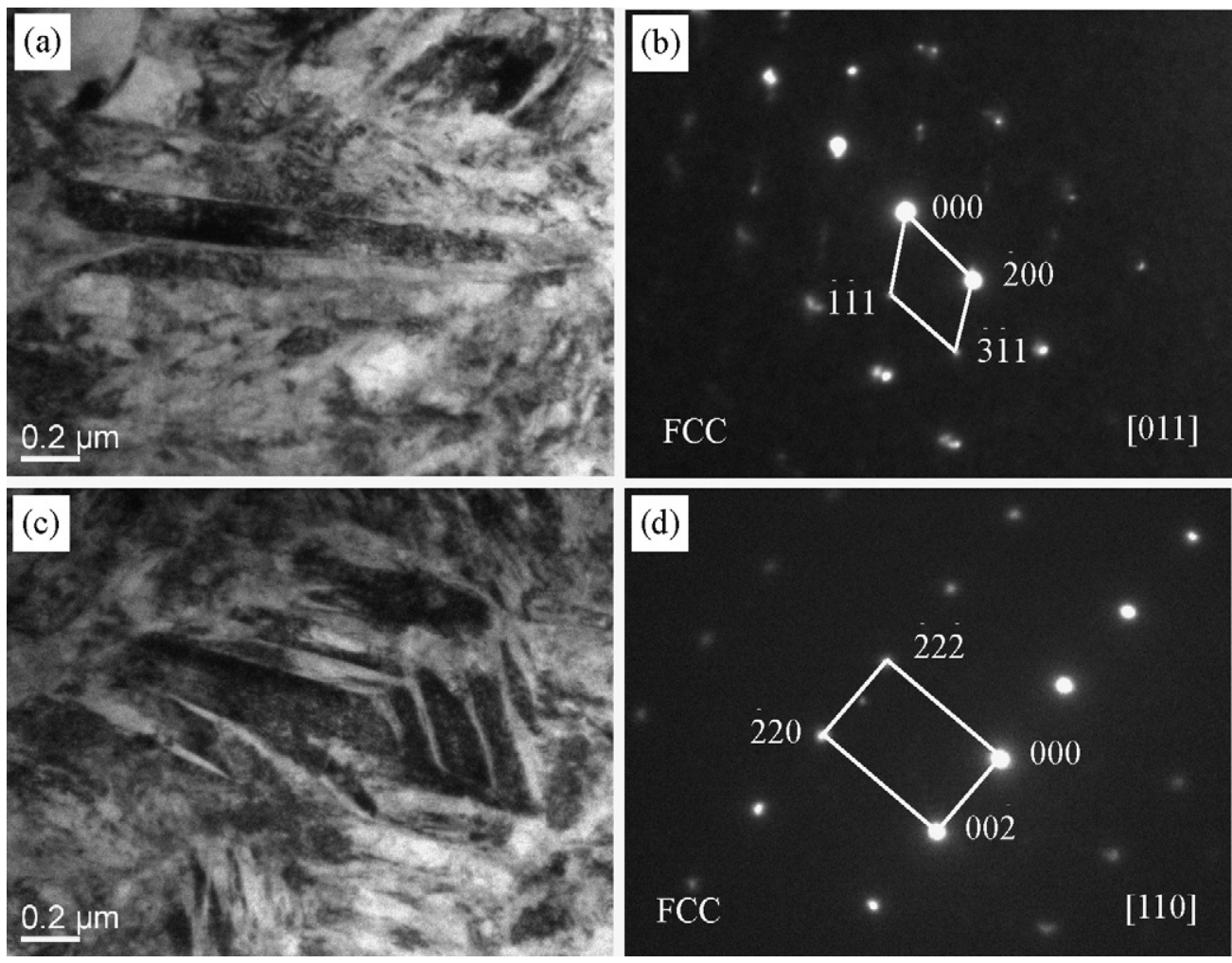

Fig. 5. Hydrides of $0.3 \% \mathrm{H}(\mathrm{a}, \mathrm{b})$ and $0.5 \% \mathrm{H}(\mathrm{c}, \mathrm{d})$ specimens deformed at $800^{\circ} \mathrm{C}$ and $0.1 \mathrm{~s}^{-1}$ (a, c) hydrides $\delta$; (b, d) SAED patterns of $\delta$. 

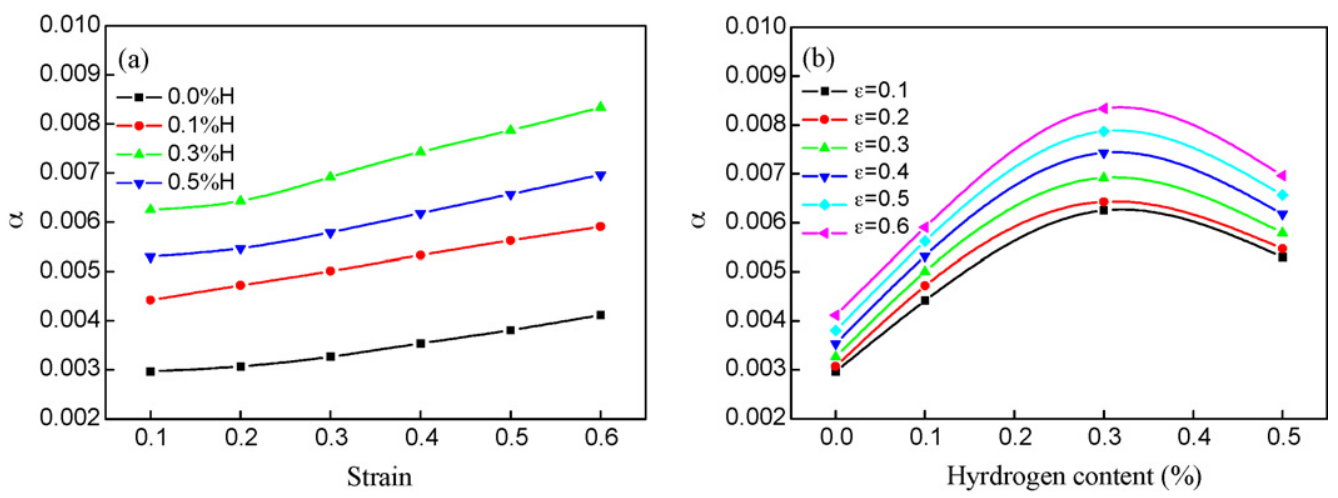

Fig. 6. Influence of strain and hydrogen content on the value of $\alpha$ of Ti600 alloy. (a) plots of $\alpha$ vs. strain; (b) plots of $\alpha$ vs. hydrogen content.
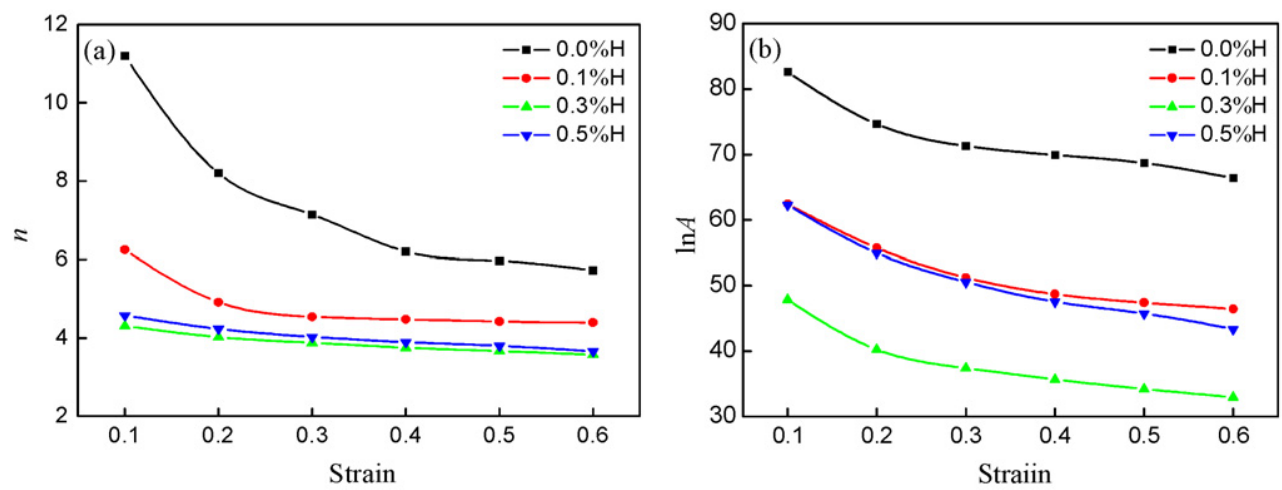

Fig. 7. Influence of strain on the values of $n$ and $\ln A$ of hydrogenated Ti600 alloy. (a) plots of $n$ vs. strain; (b) plots of $\ln A$ vs. strain.

reason leading to flow stress increasing. Additional reason causing the flow stress increasing could be due to a short range ordering which occurs at relatively high hydrogen content [23]. Although dislocation glide is expected to destroy such ordering, it may be restored continuously during deformation processing because of the high mobility of hydrogen.

\subsection{Influence of hydrogen on activation energy}

Arrhenius equations are often employed to study the influence of temperature and strain rate on flow stress. There are three Arrhenius-type equations that have been widely used to describe the relationships between stress and temperature as well as strain rate $[34,35]$ :

$\dot{\varepsilon}=A_{1} \sigma^{n_{1}} \exp (-Q / R T)$
$\dot{\varepsilon}=A_{2} \exp \left(n_{2} \sigma\right) \exp (-Q / R T)$

$\dot{\varepsilon}=A[\sinh (\alpha \sigma)]^{n} \exp (-Q / R T)$

where $n, n_{1}$ and $n_{2}$ are the stress exponents closely related to the strain rate, $A, A_{1}, A_{2}$ and $\alpha$ are material constants, $Q$ is the activation energy of deformation, $R$ is the gas constant, $T$ is the absolute temperature, $\sigma$ is flow stress, and $\dot{\varepsilon}$ is strain rate. The parameters $n_{1}$ and $n_{2}$ are obtained by the slopes of $\ln \sigma$ versus $\ln \dot{\varepsilon}$ and $\sigma$ versus $\ln \dot{\varepsilon}$ plots at a given temperature, and the value of $\alpha$ is calculated by $\alpha=n_{2} / n_{1}$. In this calculation, the values of $\alpha$ are obtained using the stress data at various strain levels and is assumed as a constant for a given strain, regardless of the influence of temperature. The influence of strain and hydrogen content on $\alpha$ is shown in Fig. 6. It can be seen that the values of $\alpha$ increase with increasing strain. The addition of hydrogen leads to an increase in $\alpha$. However, when the hydrogen content exceeds $0.3 \%$, the trend
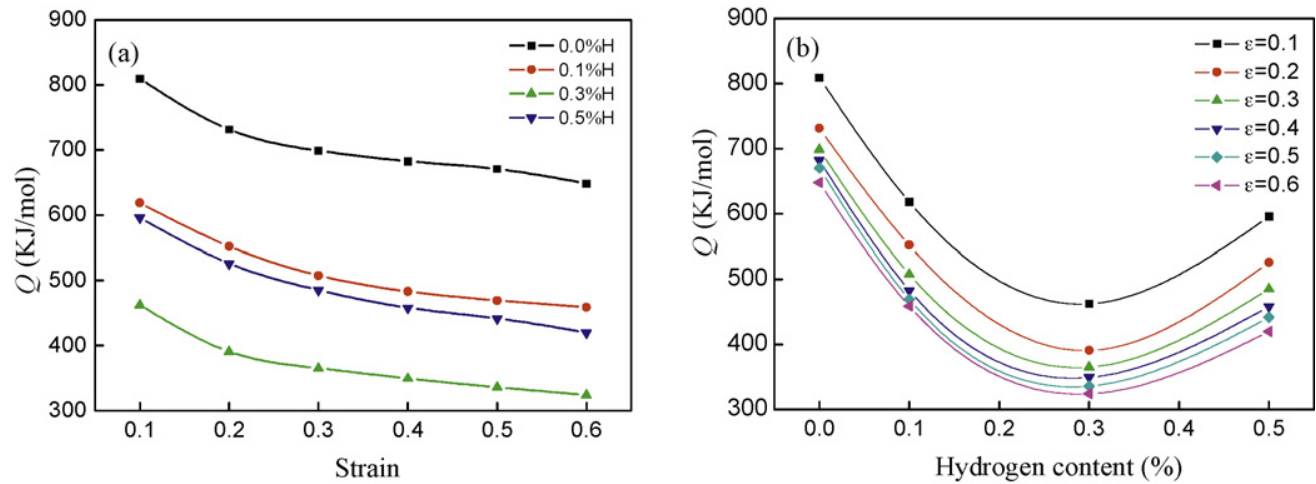

Fig. 8. Influence of strain and hydrogen content on activation energy of deformation of Ti600 alloy. (a) plots of $Q$ vs. strain; (b) plots of $Q$ vs. hydrogen content. 
is reversed and the values of $\alpha$ decrease with increasing hydrogen content. that:

Taking the natural logarithm on both sides of Eq. (3), it follows

$\ln \dot{\varepsilon}=\ln A+n \ln [\sinh (\alpha \sigma)]-(Q / R T)$

For a given temperature and strain, the slope of a $\ln \dot{\varepsilon}$ versus $\ln [\sinh (\alpha \sigma)]$ plot gives the parameter $n$ by:

$n=\frac{\partial \ln \dot{\varepsilon}}{\partial \ln [\sinh (\alpha \sigma)]}$

And the activation energy of deformation $Q$ can be acquired at given temperature and strain rate values after some mathematical manipulation:

$Q=R \frac{\partial \ln \dot{\varepsilon}}{\partial \ln [\sinh (\alpha \sigma)]} \cdot \frac{\partial \ln [\sinh (\alpha \sigma)]}{\partial(1 / T)}$

Fig. 7a and b show the stress exponent, $n$ and $\ln A$ as a function of strain at different hydrogen contents. It can be seen that the values of $n$ and $\ln A$ vary regularly with the strain level. Both $n$ and $\ln A$ decrease with increasing strain and finally reach a steady state value at higher strain levels. The values of $n$ and $\ln A$ decrease synchronously with increasing hydrogen content in the hydrogen range of 0 to $0.3 \%$. However, at the hydrogen content of $0.5 \%$, both $n$ and $\ln A$ increase compared with that of $0.3 \% \mathrm{H}$.

Bendersky et al. [36] pointed out that the strain does not affect the activation energy of deformation. But, $\mathrm{Pu}$ [35] and Radovi [37] found that the activation energy of deformation is related to the strain. Drobnjak et al. [38] had concluded that the deformation temperature and strain would affect the activation energy of deformation. According to the present experimental data, the influence of strain and hydrogen content on activation energy of deformation is illustrated in Fig. 8. It can be seen that the values of $Q$ decrease with increasing strain (Fig. 8a). A decrease of activation energy of deformation with increasing strain level indicates an accumulation of stored energy due to the hot deformation. At strain 0.6 , the calculated values of $Q$ are $648.4,459.0,324.3$ and $420.0 \mathrm{~kJ} / \mathrm{mol}$ with hydrogen contents of $0,0.1 \%, 0.3 \%$ and $0.5 \%$, respectively. The value of $Q$ decreases gradually with increasing hydrogen content in the hydrogen range of 0 to $0.3 \%$. Differently, when the hydrogen content reaches $0.5 \%$, the value of $Q$ increases compared with that of $0.3 \% \mathrm{H}$ (Fig. 8b). After hydrogenation, the value of $Q$ shows corresponding variable tendency with that of flow stress.

\section{Conclusions}

Isothermal hot compression tests were performed on Ti600 alloy after THT to study hot deformation behavior and microstructural evolution. The main conclusions to be drawn from this work follow:

(1) The flow stress of Ti600 alloy decreases gradually with increasing hydrogen content in the hydrogen range of 0 to $0.3 \%$. The addition of $0.3 \%$ hydrogen in Ti600 alloy can decrease the hot deformation temperature by $80^{\circ} \mathrm{C}$ and increase the deformation strain rate by two orders of magnitude.
(2) After hydrogenation, dynamic recrystallization is promoted. Hydrides $\delta$ exist in the specimens with $0.3 \%$ and $0.5 \%$ hydrogen, and the hydrides tend to be broken up and twisted with increasing hydrogen content after deformation.

(3) The activation energy of deformation decreases with increasing strain at a given hydrogen content level. The value of activation energy of deformation decreases gradually with increasing hydrogen content in the hydrogen range of 0 to $0.3 \%$.

(4) The addition of 0 to $0.3 \%$ hydrogen can decrease the flow stress and activation energy of deformation of Ti600 alloy when deformed at the temperature range of 760 to $880^{\circ} \mathrm{C}$.

\section{References}

[1] R.A. Oriani, Acta Metall. 18 (1970) 147-157.

[2] G.M. Pressouyre, I.M. Bernstein, Corros. Sci. 18 (1978) 819-833.

[3] G.M. Pressouyre, I.M. Bernstein, Acta Metall. 27 (1979) 89-100.

[4] G.M. Pressouyre, Acta Metall. 28 (1980) 895-911.

[5] E. Abramov, D. Eliezer, Scripta Metall. Mater. 24 (1990) 1387-1392.

[6] E. Abramov, G. Solovioff, D. Eliezer, J. Nucl. Mater. 212/215 (1994) 1406-1410.

[7] N.H. Nickel, J. Non-Cryst. Solids 198/200 (1996) 46-51.

[8] C.L. Briant, Z.F. Wang, N. Chollocoop, Corros. Sci. 44 (2002) 1875-1888.

[9] R.J. Elias, H.L. Corso, J.L. Gervasoni, Int. J. Hydrogen Energy 27 (2002) 91-97.

[10] B.A. Kolachev, A.A. Ilyin, V.K. Nosov, Advances in the Science and Technology of Titanium Alloy Processing. Proceedings of an International Symposium held at 125th TMS Annual Meeting, TMS, Warrendale, PA, USA, 1996 pp. 331-338.

[11] N. Eliaz, D. Eliezer, D.L. Olson, Mater. Sci. Eng. A 289 (2000) 41-53.

[12] D. Eliezer, N. Eliaz, O.N. Senkov, F.H. Froes, Mater. Sci. Eng. A 280 (2000) 220-224.

[13] O.N. Senkov, F.H. Froes, Int. J. Hydrogen Energy 24 (1999) 565-576.

[14] E. Tal-Gutelmacher, D. Eliezer, Th. Boellinghaus, J. Alloys Compd. 440 (2007) 204-209.

[15] D.B. Shan, Y.Y. Zong, Y. Lv, B. Guo, Scripta Mater. 58 (2008) 449-452.

[16] M.Q. Li, W.F. Zhang, Int. J. Hydrogen Energy 33 (2008) 2714-2720.

[17] B.A. Kolachov, L.A. LivanoV, V.K. Nosov, Titanium and Titanium Alloys: Scientific and Technological Aspects (Proceedings of the 3rd International Conference on Titanium), New York, Plenum Press, USA, 1982, pp. 1833-1842.

[18] Y. Zhang, S.Q. Zhang, Scripta Mater. 37 (1997) 1315-1321.

[19] S.Q. Zhang, L.R. Zhao, J. Alloys Compd. 218 (1995) 233-236

[20] Y.Y. Zong, D.B. Shan, Y. Lü, B. Guo, Int. J. Hydrogen Energy 32 (2007) 3936-3940.

[21] J.J. Xu, H.Y. Cheung, S.Q. Shi, J. Alloys Compd. 436 (2007) 82-87.

[22] C.-T. Liu, T.-I. Wu, J.-K. Wu, Mater. Chem. Phys. 110 (2008) 440-444.

[23] Z.G. Sun, W.L. Zhou, H.L. Hou, Int. J. Hydrogen Energy 34 (2009) 1971-1976.

[24] J.Q. Lu, J.N. Qin, W.J. Lu, D. Zhang, H.L. Hou, Z.Q. Li, Mater. Sci. Eng. A 550 (2009) $1-7$.

[25] D. Weinem, J. Kumpfert, M. Peters, W.A. Kaysser, Mater. Sci. Eng. A 206 (1996) 55-62.

[26] R.W. Evans, R.J.Hull, B. Wilshire, J. Mater. Process. Technol. 56 (1996) 492-501.

[27] V. Tetyukhin, I. Levin, V. Ilyenko, in: P.H. Blenkinsop, W.J. Evans, H.M. Flower (Eds.), Titanium'95: Science and Technology, Cambridge, the University Press, UK, 1996, pp. 2430-2437.

[28] Q. Hong, Y.L. Qi, Y.Q.Zhao, G.J. Yang, Rare Met. Mater. Eng. 34(2005) 1334-1337.

[29] Y.L. Qi, Northwestern Polytechnical University, 2007.

[30] Q. Hong, Y.L. Qi, P. Guo, L.Y. Zeng, Y.Q. Zhao, Rare Met. Lett. 26 (2007) 19-22.

[31] O.N. Senkov, J.J. Jonas, Metall. Mater. Trans. A 27A (1996) 1869-1876.

[32] D.S. Shih, I.M. Robertson, H.K. Birnbaum, Acta Metall. 36 (1998) 111-124.

[33] H.K. Birnbaum, P. Sofronis, Mater. Sci. Eng. A 176 (1994) 191-202.

[34] P. Wanjara, M. Jahazi, H. Monajati, S. Yue, J.P. Immarigeon, Mater. Sci. Eng. A 396 (2005) 50-60.

[35] Z.J. Pu, K.H. Wu, S. Shi, D. Zou, Mater. Sci. Eng. A 192/193 (1995) 780-787.

[36] L. Bendersky, A. Rosen, A.K. Mukherjee, Strength of Metals and Alloys (ICSMA 6), vol. 2, 1983, pp. 595-600.

[37] N. Radovi, D. Drobnjak, ISIJ Int. 39 (1999) 575-582.

[38] D. Drobnjak, N. Radovi, M. Andjeli, Steel Res. 68 (1997) 306-312. 